\title{
Study on round rice straw bale wrapping silage technology and facilities
}

\author{
Liqiao $\mathrm{Li}^{1,2}$, Defu Wang ${ }^{1,2^{*}}$, Xing Yang ${ }^{1}$ \\ (1. College of Engineering, Northeast Agricultural University, Harbin 150030, China; \\ 2. Key Laboratory of Swine Facilities Engineering, Ministry of Agriculture, Harbin 150030, China)
}

\begin{abstract}
Specific to problems of the existing round bale wrapping machine in China, such as small application scope and failing to satisfy the wrapping demands of round bales of different specifications, a tumbler-type round bale wrapping machine based on wrapping silage with stretch film was designed. By theoretical analysis and preliminary experiments of the corresponding wrapping process, revolving speed of tumbler, speed ratio between tumbler and carrier rollers, and pre-load force of stretch film were determined as experimental factors, while wrapping time and consumption of stretch film per unit mass of round bale were determined as evaluation indexes. Furthermore, quadratic regression orthogonal rotational combination experimental design was adopted to carry out the wrapping experiment. The regression models were set up, and influencing rules of experimental factors on evaluation indexes were also analyzed. The optimal parameter combination scheme was revolving speed of tumbler of 31-32 r/min, speed ratio between tumbler and carrier rollers of 2.6, and pre-load force of stretch film of 20-22 N. Under such a circumstance, the corresponding wrapping time required was 37.7-38.9 s and consumption of stretch film per unit mass of round bale was 3.21-3.46 kg/t. The predicted values and the measured values of evaluation indexes basically coincided with each other and the relative error fell below 5\%, which indicated that both the optimized regression models acquired through the wrapping experiment and the relevant parameter optimization results were reliable. To guarantee the quality of rice straw silage, the round bale should be wrapped by no less than five layers of stretch films through the utilization of the tumbler-type round bale wrapping machine. The study results could be used as references for research and development of the round bale wrapping machine.
\end{abstract}

Keywords: round bale, silage, wrapping machine, tumbler-type, analysis, experiment

DOI: $10.25165 /$ j.ijabe.20181104.2855

Citation: Li L Q, Wang D F, Yang X. Study on round rice straw bale wrapping silage technology and facilities. Int J Agric \& Biol Eng, 2018; 11(4): 88-95.

\section{Introduction}

With an annual output up to $0.6-0.8$ billion tons ${ }^{[1,2]}$, the extremely abundant crop straw resources in China can be utilized as feeds, fuels, fertilizers and industrial raw materials, etc. ${ }^{[2,3]}$ To be specific, when rice straws are utilized as feeds, the traditional way of loose outdoor stacking gives rise to deduction in nutrition ingredients (with a loss rate reaching 30\%-50\%) and poor palatability ${ }^{[4]}$. In comparison, baling and wrapping straws in green state while harvesting grain to produce straw silage is an effective solution to problems above ${ }^{[5,6]}$.

In countries with developed animal husbandry, the round bale wrapping machine had begun to blossom in the 1980s. At present, series products of the wrapping machine have been developed. In detail, the major diameter and length of round bales, which can be wrapped by the wrapping machine, range from $1000 \mathrm{~mm}$ to $1500 \mathrm{~mm}$. And, the developing tendency of the wrapping machines is large-scaling, automation and integration of baling and wrapping $^{[7-9]}$, e.g., Sideliner 1650A-type wrapping machine (ELHO Company, Sweden). Studies on the wrapping machine started

Received date: 2016-09-15 Accepted date: 2018-04-12

Biographies: Liqiao Li, PhD candidate, research interest: livestock machinery, Email: liliqiao1108@163.com; Xing Yang, Master, research interest: livestock machinery, Email: 592841412@qq.com.

*Corresponding author: Defu Wang, $\mathrm{PhD}$, Professor, research interest: livestock machinery. Mailing address: College of Engineering, Northeast Agricultural University, Harbin, Heilongjiang 150030, China. Tel: +86-45155191712, Email: dfwang0203@163.com. relatively late in China, and existing wrapping devices are predominant by the small machine which cannot satisfy the wrapping demands of round bales obtained by the round baler available (major diameter/length between $500 \mathrm{~mm}$ and $1000 \mathrm{~mm})^{[10]}$. Moreover, the wrapping machines developed in foreign countries require large powers and higher prices so that it is less likely to meet the practical wrapping needs of round bales in China ${ }^{[10]}$. Therefore, it is very necessary to develop wrapping machines applicable to meet the above mentioned needs.

Currently, although the performance of wrapping silage has been extensively studied by overseas scholars ${ }^{[11-18]}$, studies on parameter optimization for round bale wrapping machine are rare. In China, relevant scholars ${ }^{[4,6,19]}$ primarily carry out studies on turntable wrapping machine in which the turntable drives round bale to rotate meanwhile the turntable revolves. However, the wrapping manner of such an approach has many problems, such as strict restrictions on diameter and length of the round bale.

To boost the development of rice straw bale silage technology, a tumbler-type round bale wrapping machine based on wrapping silage with stretch film (the tumbler driving stretch film to revolve around the round bale, while carrier rollers driving the round bale to rotate) was designed and it could be regulated based on round bales of different specifications. By theoretical analysis and experimental study on the wrapping process of the wrapping machine, the optimal parameter combination scheme was explored together with performance testing for round rice straw bale wrapping silage. Hopefully, references could be provided for research and development of the round bale wrapping machine. 


\section{Methods and materials}

\subsection{Design of round bale wrapping machine and analysis on its wrapping process}

2.1.1 Overall structure and operating principle of tumbler-type round bale wrapping machine

The main components of the tumbler-type round bale wrapping machine include main frame, carrier roller institution, tumbler wrapping unit and transmission mechanism, etc., as shown in Figure 1. The whole size of the machine is $1900 \mathrm{~mm}$ (length) $\times$ $1100 \mathrm{~mm}$ (width) $\times 2000 \mathrm{~mm}$ (height), applicable to the wrapping demands of round bales with a diameter/length between $500 \mathrm{~mm}$ and $1000 \mathrm{~mm}$. Carrier roller institution and tumbler wrapping unit are key parts of this machine, of which the former is composed of two carrier rollers mounted in parallel and two position limitation rollers on both ends of carrier rollers, etc., while the latter is formed by tumbler, bracket and film delivery device, etc.. Furthermore, carrier rollers and tumbler are driven by XWD-1.5-type and XWD-2.2-type cycloid retarders (the reduction ratio of both is 17:1) and controlled by FR-F740-45K-CHT1-type (Japanese Mitsubishi Company) and MICROMASTER440-type (Siemens AG) converters, respectively.

During wrapping, the round bale is firstly placed between two carrier rollers, and the axis of the round bale is located in the vertical plane that has the same distance from axes of two carrier rollers, and ends of the round bale are located by position limitation rollers. Then, carrier roller institution drives round bale to rotate by the frictions between carrier rollers and round bale. Meanwhile, film delivery device is driven to revolve around the bale by tumbler. Through the compound movements of the two institutions mentioned above, stretch film evenly twines around the round bale layer by layer. After the required wrapping layers are obtained, stretch film is cut off. Different layers are not to loosen by virtue of surface adhesion possessed by stretch film ${ }^{[4]}$. Thus, the wrapping operation is completed.

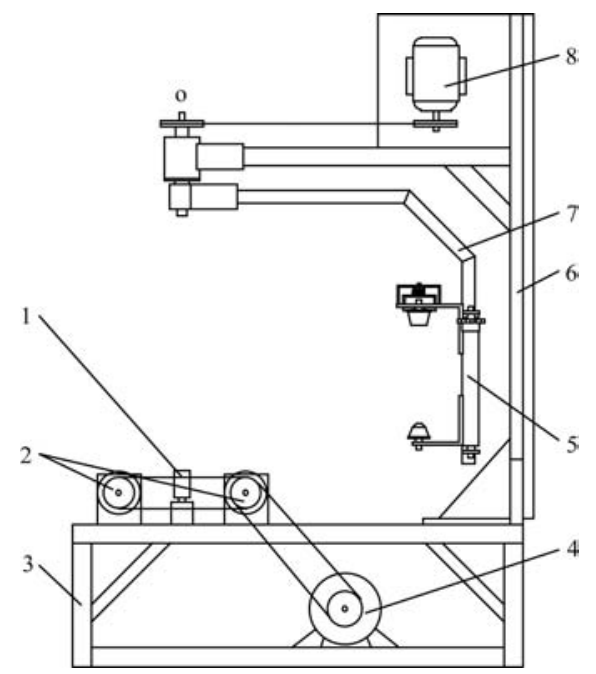

1. Position limitation roller 2. Carrier roller 3. Main frame 4. Carrier roller retarder 5 . Film delivery device 6 . Bracket $\quad 7$. Tumbler 8 . Tumbler retarder Figure 1 Schematic diagram for overall structure of tumbler-type round bale wrapping machine

\subsubsection{Design of carrier roller institution}

Carrier roller institution is mainly constituted by carrier rollers, position limitation rollers, connecting plate, retaining plate, lead screw, guide rod and sliding block, etc.

According to the dimension of round bales obtained from the existing round baler and the relevant literature ${ }^{[20]}$, the diameter and the length of carrier rollers are determined to be $145 \mathrm{~mm}$ and $1100 \mathrm{~mm}$ respectively; moreover, wrapping can be carried out for the round bale no longer than $1000 \mathrm{~mm}$. In order to increase the frictions between carrier rollers and round bale, ten ribs with a height of $5 \mathrm{~mm}$ are circumferentially and evenly arranged along the external surface of each carrier roller. In addition, to satisfy the wrapping demands of round bales of different specifications in China, the distance between center axis lines of two carrier rollers is set as adjustable.

To locate ends of the round bale of different lengths and reduce the frictions between position limitation rollers and round bale, two turntable position limitation rollers are established on both ends of carrier rollers additionally, and the axes of position limitation rollers are located in the vertical plane that has the same distance from axes of two carrier rollers. By adjusting the lead screw, symmetric motions of position limitation rollers are realized due to the opposite turning directions of screw threads on each end. At the same time, to acquire a certain distance between position limitation rollers and round bale, according to the relevant literature $^{[20]}$, the diameter and the length of position limitation rollers are determined to be $50 \mathrm{~mm}$ and $100 \mathrm{~mm}$ respectively.

According to the position relationships between two carrier rollers and round bale, it is clear that the vertical distance between the center of gravity of the round bale and the connection line of centers of end faces of two carrier rollers should satisfy the following formula:

$$
\left\{\begin{array}{l}
\left(\frac{a}{2}\right)^{2}+h^{2}=(R+r)^{2} \\
\cot \theta=\frac{a}{2 h}
\end{array}\right.
$$

where, $a$ is the distance between center axis lines of two carrier rollers, $\mathrm{mm} ; h$ is the vertical distance between the center of gravity of the round bale and the connection line of centers of end faces of two carrier rollers, $\mathrm{mm} ; R$ is the radius of the round bale, $\mathrm{mm} ; r$ is the radius of carrier rollers, $72.5 \mathrm{~mm} ; \theta$ is the included angle between the horizontal line, and the connection line of centers of end faces of the round bale and the left carrier roller, $\left(^{\circ}\right)$.

According to Equation (1), when the radius of the round bale $(R)$ is invariant and the distance between center axis lines of two carrier rollers $(a)$ increases, $h$ descends, in other words, the center of gravity of the round bale relative to carrier rollers moves down. Moreover, if $h$ is excessively small, stretch film fails to get through the center of end faces of the round bale normally during wrapping, which affect the wrapping quality. However, when $a$ decreases, $h$ increases otherwise; that is, the center of gravity of the round bale relative to carrier rollers moves up. But if $h$ is excessively big, it is more likely for the round bale to lose balance during wrapping to incur tumbling.

Therefore, it is beneficial to improve both the wrapping quality and the stability of the round bale when the distance between center axis lines of two carrier rollers $(a)$ is appropriately selected. To ensure the stability of round bales and carry out the wrapping experiment smoothly, $h$ is determined to be $3 R / 4$ according to the relevant literature ${ }^{[19]}$ and preliminary experiments. According to Equation (1) and the above analysis, when the radius of the round bale $(R)$ is equal to $250 \mathrm{~mm}, a$ is $525 \mathrm{~mm}$ and $\theta$ is $36^{\circ}$. By contrast, when $R$ is equal to $500 \mathrm{~mm}, a$ and $\theta$ become $865 \mathrm{~mm}$ and $41^{\circ}$ respectively. Therefore, in terms of such a tumbler-type round bale wrapping machine, the adjustable range of $a$ is 525$865 \mathrm{~mm}$ and $\theta$ is permitted to vary between $36^{\circ}$ and $41^{\circ}$. 


\subsubsection{Design of tumbler wrapping unit}

Among tumbler wrapping unit, tumbler is mainly adopted to fasten film delivery device and drive it to revolve around the round bale. After the overall structure of such a tumbler-type round bale wrapping machine and round bale dimensions wrapped by it have been taken into a comprehensive account, the turning radius of tumbler and the height of bracket are determined to be $1000 \mathrm{~mm}$ and $1630 \mathrm{~mm}$ respectively.

The film delivery device is constituted by upper/lower membrane bracket, membrane dead plate, membrane guiding roller, pre-load regulator, friction plate and spring etc. Among these mechanisms, the upper/lower membrane bracket is mainly used to fasten stretch film. According to the width of common stretch film in China (250-300 $\mathrm{mm}$ ), the adjustable range of upper/lower membrane dead plate is determined to range from $240 \mathrm{~mm}$ to $350 \mathrm{~mm}$. Two membrane guiding rollers are employed to guarantee the smoothness of stretch film during wrapping, and able to rotate around its own axis respectively. According to the size of stretch film paper tube core, the diameter and the length of the membrane guiding rollers are defined as $45 \mathrm{~mm}$ and $410 \mathrm{~mm}$ respectively. In addition, uniform decorative patterns are set on its surface to increase the frictions between membrane guiding rollers and stretch film. With regard to the pre-load regulator, it is composed by friction plate, spring, pressure plate and adjusting screw nut, etc., and principally used to provide certain pre-load force when stretch film turns. Besides, the spring compresses the upper membrane bracket tightly by virtue of the friction plate to change the magnitude of frictional resistance, which is generated during the rotation of the upper membrane bracket by adjusting the elastic force of spring. In this way, pre-load force of stretch film is regulated.

\subsubsection{Analysis of the wrapping process}

During wrapping, the round bale is under actions of its own gravity, tensile force exerted on it by stretch film, normal support forces from two carrier rollers, as well as the frictions between carrier rollers and the round bale, as shown in Figure 2.

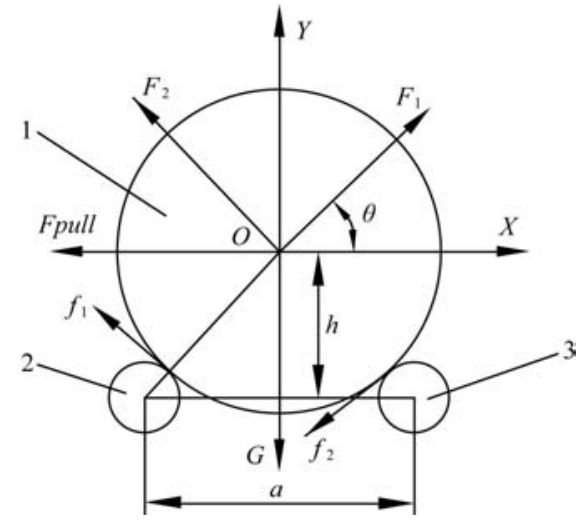

1. Round bale 2. Left carrier roller 3. Right carrier roller

Figure 2 Force analysis of the round bale

Through preliminary experiments, tensile force exerted on the round bale by stretch film has a rather substantial influence on the wrapping quality and the stability of the round bale. When tensile force is oversized, it is liable to cause the tumble of the round bale due to imbalance. At this time, both normal support force from the right carrier roller and the friction between the right carrier roller and the round bale are zero. As a consequence, critical state of the round bale at the beginning of rolling down should be analyzed. The corresponding computational formula for the torque along $X$-axis and $Y$-axis is

$$
\left\{\begin{array}{l}
F_{p u l l} L=F_{1} \frac{L}{2} \cos \theta-f_{1} \frac{L}{2} \sin \theta \\
G=F_{1} \sin \theta \\
f_{1}=\mu F_{1}
\end{array}\right.
$$

where, $F_{\text {pull }}$ is tensile force exerted on the round bale by stretch film, $\mathrm{N} ; G$ is gravity of the round bale, $\mathrm{N} ; F_{1}$ is normal support force from the left carrier roller, $\mathrm{N} ; f_{1}$ is friction force between the left carrier roller and the round bale, $\mathrm{N} ; L$ is the length of the round bale, $\mathrm{mm} ; \mu$ is the friction coefficient between the left carrier roller and the round bale; $\theta\left(^{\circ}\right)$ is the included angle between $F_{1}$ and the horizontal line, and equivalent to $\theta$ given in Equation (1).

Based on Equation (2), $F_{\text {pull }}$ (tensile force exerted on the round bale by stretch film) should satisfy the following formula during wrapping:

$$
F_{\text {pull }} \leq \frac{G}{2}(-\mu+\cot \theta)
$$

Furthermore, according to Equation (3) and the analysis results related to Equation (1), tensile force exerted on the round bale by stretch film $\left(F_{\text {pull }}\right)$ is related to gravity of the round bale $(G)$, the radius of the round bale $(R)$, and the friction coefficient between the left carrier roller and the round bale $(\mu)$. When the mass of the round bale with a radius of $250 \mathrm{~mm}$ is $36 \mathrm{~kg}$, in line with Equation (3) and the analysis result related to Equation (1) $\left(\theta=36^{\circ}\right)$, it is clear that critical value of $F_{\text {pull }}$ is $158 \mathrm{~N}$. Therefore, in order to ensure the stability of round bales during wrapping, pre-load force of stretch film should be less than $158 \mathrm{~N}$.

From preliminary experiments, it can be known that the proportion taken by overlap width between two adjacent rounds of stretch films in the total width of stretch film (hereinafter referred to as overlapping ratio of stretch films) directly affects the wrapping quality. Lack of overlapping ratio of stretch films gives rise to poor leakproofness after wrapping; otherwise, excessive overlapping ratio of stretch films with preferable leakproofness causes wastes of stretch film and increases the wrapping cost.

As tumbler has a revolving speed faster than that of the round bale, ideal state is used to perform the corresponding analysis for the sake of simplifying problems. Overlapping ratio of stretch films can be obtained by the following equation:

$$
\left\{\begin{array}{l}
M=\left(\frac{l-b}{l}\right) \times 100 \% \\
b=\omega r t \\
\omega=\frac{2 \pi n_{1}}{60} \\
t=\frac{60}{n_{2}}
\end{array}\right.
$$

where, $M$ is overlapping ratio of stretch films, $\% ; l$ is the width of stretch film, $250 \mathrm{~mm} ; b$ is the distance staggered between two adjacent rounds of stretch films, $\mathrm{mm}$; $\omega$ is angular speed of carrier roller, $\mathrm{rad} / \mathrm{s} ; t$ is the time required by tumbler to make a round around the round bale, $\mathrm{s} ; n_{1}$ is revolving speed of carrier rollers, $\mathrm{r} / \mathrm{min} ; n_{2}$ is revolving speed of tumbler, $\mathrm{r} / \mathrm{min}$.

According to Equation (4), overlapping ratio of stretch films $(M)$ should satisfy the following formula during wrapping:

$$
M=\left(1-\frac{1.8}{k}\right) \times 100 \%
$$

where, $k$ denotes the ratio of revolving speed of tumbler $\left(n_{2}\right)$ to revolving speed of carrier rollers $\left(n_{1}\right)$, hereinafter referred to as 
"speed ratio between tumbler and carrier rollers".

It can be known from Equation (5) that different speed ratios between tumbler and carrier rollers correspond to different overlapping ratios of stretch films. While the former is based on revolving speed of tumbler, revolving speed of tumbler directly affects wrapping efficiency.

Relying on the above analysis, revolving speed of tumbler, speed ratio between tumbler and carrier rollers, and pre-load force of stretch film are key influencing factors of the wrapping quality and efficiency. Therefore, the study should focus on the three parameters with an expectation to improve the working performance of the tumbler-type round bale wrapping machine, then prototype experiment was carried out to mainly explore influencing rules of the key factors on the major performance indexes.

\subsection{Experimental materials and devices}

Round rice straw bales of $\varnothing 500 \mathrm{~mm} \times 750 \mathrm{~mm}$ were selected as the experimental materials. As for the corresponding stretch film, twining plastic membrane for exclusive use (thickness, $0.025 \mathrm{~mm}$; width, $250 \mathrm{~mm}$ ) was adopted.

Apparatus and devices used for the wrapping experiment included a self-developed tumbler-type round bale wrapping machine, DGL-50-type ergometer (division value, $0.2 \mathrm{~N}$; force measurement scope, 0.2-500 N; manufactured by Fuzhou Furi Electronics Co., Ltd.), BSA3202S-type electronic scales (resolution, $0.01 \mathrm{~g}$; maximum capacity, $3200 \mathrm{~g}$; manufactured by Sartorius Science Apparatus Co., Tld.), and a stopwatch.

\subsection{Experimental methods}

\subsubsection{Experimental factors}

According to the above analysis and preliminary experiments, revolving speed of tumbler $\left(n_{2}\right)$, speed ratio between tumbler and carrier rollers $(\psi)$, and pre-load force of stretch film $\left(F_{p l}\right)$ were determined as experimental factors and analyzed as follows.

According to preliminary experiments, when revolving speed of tumbler $\left(n_{2}\right)$ was higher than $35 \mathrm{r} / \mathrm{min}$, the round bale became unstable during wrapping; but, when $n_{2}$ was lower than $8 \mathrm{r} / \mathrm{min}$, it gave rise to extremely low productivity and bulging. Therefore, the value range for $n_{2}$ should be between $8 \mathrm{r} / \mathrm{min}$ and $35 \mathrm{r} / \mathrm{min}$.

According to Equation (5), in the case that two adjacent rounds of stretch films failed to overlap exactly at the time of round bale wrapping, that is, the leakproofness of wrapping was rather poor, speed ratio between tumbler and carrier rollers $(\psi)$ was 1.8 . However, when overlapping ratio of stretch films reached $60 \%$, $\psi$ turned to 4.6 , then stretch film wastes were inevitable despite of preferable wrapping leakproofness. Hence, $\psi$ should range from 1.8 to 4.6 .

According to preliminary experiments, when pre-load force of stretch film $\left(F_{p l}\right)$ went beyond $23 \mathrm{~N}$, the problem of film breaking might rise during wrapping sometimes. In comparison, if $F_{p l}$ was just $23 \mathrm{~N}$, both the wrapping quality and compactness were favorable; and, in the case of being no more than $23 \mathrm{~N}$, appropriate increase in $F_{p l}$ could intensify the wrapping compactness so as to improve the wrapping quality further. Moreover, when $F_{p l}$ was less than $6 \mathrm{~N}$, rather poor wrapping quality and compactness were obtained. According to the fact that the number of wrapping layers was four and overlapping ratio of stretch films was $30 \%$, round fresh rice straw bale wrapping silage experiment was carried out in Heilongjiang Province. After forty-five days of wrapping silage, the quality of rice straw bale wrapping silage was detected to be at an inferior grade when $F_{p l}$ was $6 \mathrm{~N}$. Nevertheless, it turned out to be good if $F_{p l}$ was $23 \mathrm{~N}$. That is, with the increase in
$F_{p l}$, the quality of rice straw bale wrapping silage could be improved correspondingly. On this basis, pre-load force of stretch film had an enormous impact on the quality of round fresh rice straw bale wrapping silage, which was mainly caused by substantial influences of the former on wrapping sealing performance of the round rice straw bale. Therefore, taking into comprehensive consideration of round bale stability and wrapping compactness, the value range of $F_{p l}$ was determined to be between $6 \mathrm{~N}$ and $23 \mathrm{~N}$.

2.3.2 Evaluation indexes

According to the relevant literatures ${ }^{[21-22]}$, theoretical analysis and preliminary experiments, the evaluation indexes related are defined as follows:

1) Wrapping time $(T)$

It refers to the time required by the completion of four-layer wrapping for a single round bale, kept from the starting of retarder.

2) Consumption of stretch film per unit mass of round bale $(G)$

It refers to the ratio of the stretch film mass required by the completion of four-layer wrapping for such a single round bale to the round bale mass. It should satisfy the following formula:

$$
G=\frac{G_{1}}{G_{2}}
$$

where, $G$ is consumption of stretch film per unit mass of round bale, $\mathrm{kg} / \mathrm{t} ; G_{1}$ is the stretch film mass for a single round bale, $\mathrm{kg} ; G_{2}$ is the round bale mass, $\mathrm{t}$.

\subsubsection{Experimental design scheme}

In order to explore influences of revolving speed of tumbler $\left(n_{2}\right)$, speed ratio between tumbler and carrier rollers $(\psi)$, and pre-load force of stretch film $\left(F_{p l}\right)$ on wrapping time $(T)$ and consumption of stretch film per unit mass of round bale $(G)$, the experimental method of quadratic regression orthogonal rotational combination with three factors of five levels each was adopted. Levels and codes of experimental factors is shown in Table 1. Experimental design scheme is shown in Table 2.

Table 1 Levels and codes of experimental factors

\begin{tabular}{lccc}
\hline \multicolumn{1}{c}{ Levels } & $n_{2} / \mathrm{r} \cdot \mathrm{min}^{-1}$ & $\psi$ & $F_{p l} / \mathrm{N}$ \\
\hline Lower asterisk arm -1.682 & 8 & 1.8 & 6 \\
Lower level -1 & 13.5 & 2.4 & 9.5 \\
Zero level 0 & 21.5 & 3.2 & 14.5 \\
Upper level 1 & 29.5 & 4 & 19.5 \\
Upper asterisk arm 1.682 & 35 & 4.6 & 23 \\
Varying space & 8 & 0.8 & 5 \\
\hline
\end{tabular}

\section{Results and discussion}

\subsection{Experimental results}

For the purpose of reducing experimental errors, twenty-three groups of experiments designed in the scheme were repeated for ten times each and the mean value was used as the experimental result $^{[23-26]}$. And, there were nine groups of zero-level experiments as they could estimate experimental errors and then test the fitting condition of the predicted values and the measured values of regression models in the whole regression region, and the set of nine groups of zero-level experiments could ensure that the quadratic regression rotational combination experimental design had the characteristics of orthogonality or almost orthogonality, which meant that there were no correlation between the regression coefficients in addition to constant term regression coefficient and square term regression coefficient. Experimental design scheme and results are shown in Table 2. Where, $A, B$ and $C$ are the code 
(a professional term of "numerical analysis and mathematical statistics" ${ }^{[27]}$ ) of revolving speed of tumbler $\left(n_{2}\right)$, speed ratio between tumbler and carrier rollers $(\psi)$, and pre-load force of stretch film $\left(F_{p l}\right)$, respectively. The specific values of $A, B$ and $C$ are $-1.682,-1,0,1$ and 1.682 .

Table 2 Experimental design scheme and results

\begin{tabular}{|c|c|c|c|c|c|}
\hline \multirow{2}{*}{ No. } & \multicolumn{3}{|c|}{ Experimental factors } & \multicolumn{2}{|c|}{ Evaluation indexes } \\
\hline & $A$ & $B$ & $C$ & $T / \mathrm{s}$ & $G / \mathrm{kg} \cdot \mathrm{t}^{-1}$ \\
\hline 1 & -1 & -1 & -1 & 68.0 & 4.13 \\
\hline 2 & 1 & -1 & -1 & 31.7 & 3.72 \\
\hline 3 & -1 & 1 & -1 & 102.4 & 6.42 \\
\hline 4 & 1 & 1 & -1 & 45.6 & 5.91 \\
\hline 5 & -1 & -1 & 1 & 63.6 & 3.59 \\
\hline 6 & 1 & -1 & 1 & 35.8 & 3.27 \\
\hline 7 & -1 & 1 & 1 & 97.2 & 5.21 \\
\hline 8 & 1 & 1 & 1 & 48.9 & 4.80 \\
\hline 9 & -1.682 & 0 & 0 & 109.6 & 5.22 \\
\hline 10 & 1.682 & 0 & 0 & 38.0 & 4.52 \\
\hline 11 & 0 & -1.682 & 0 & 33.4 & 2.68 \\
\hline 12 & 0 & 1.682 & 0 & 75.1 & 6.02 \\
\hline 13 & 0 & 0 & -1.682 & 56.2 & 5.37 \\
\hline 14 & 0 & 0 & 1.682 & 55.3 & 3.98 \\
\hline 15 & 0 & 0 & 0 & 54.0 & 4.66 \\
\hline 16 & 0 & 0 & 0 & 56.1 & 4.61 \\
\hline 17 & 0 & 0 & 0 & 58.3 & 5.42 \\
\hline 18 & 0 & 0 & 0 & 60.3 & 5.07 \\
\hline 19 & 0 & 0 & 0 & 55.7 & 5.10 \\
\hline 20 & 0 & 0 & 0 & 58.2 & 5.03 \\
\hline 21 & 0 & 0 & 0 & 56.7 & 4.82 \\
\hline 22 & 0 & 0 & 0 & 50.6 & 5.36 \\
\hline 23 & 0 & 0 & 0 & 57.5 & 4.72 \\
\hline
\end{tabular}

\subsection{Establishment and verification of regression models}

Design-Expert software was adopted to analyze the data shown in Table 2 so as to set up regression models that could describe influences of experimental factors on evaluation indexes. Then, variance analysis was conducted targeted at all regression models ${ }^{[28]}$. The corresponding results are the data shown on the left of the oblique line in Table 3.

According to the data on the left of the oblique line in Table 3, regression models for wrapping time $(T)$ and consumption of stretch film per unit mass of round bale $(G)$ were both extremely significant $(p<0.0001)$, and lack of fit terms of both were insignificant $(p>0.1)$, which showed that all regression models were appropriate ${ }^{[23-26]}$. Regarding regression models for $T$ and $G$ obtained based on Design-Expert software, the coefficients of determination were $R_{T}^{2}=0.99$ and $R_{G}^{2}=0.96$, signifying that regression models and experimental results had a rather preferable fitting degree and small experimental errors ${ }^{[23-26]}$, and the models could be used to predict variations in $T$ and $G$ respectively. According to the significance degree of all regression terms on evaluation indexes in Table 3, not only did the fitting regression models need to be further improved, but the most insignificant regression terms should be eliminated one by one, and the squares and degrees-of-freedom were merged into the error term ${ }^{[28]}$. Subsequently, through multiple recalculations, the optimized regression models for influences of actual values of all experimental factors on $T$ and $G$ could be thus gained, as expressed in Equations (7) and (8) respectively. Besides, variance analysis was performed for all optimized regression models. The corresponding results are the data shown on the right of the oblique line of Table 3 .

$$
\begin{aligned}
& T=73.9602-5.0728 n_{2}+31.0359 \psi-1.118 F_{p l}-0.7679 n_{2} \psi+ \\
& \quad 0.052 n_{2} F_{p l}+0.0961 n_{2}^{2} \\
& G=-2.914-0.0258 n_{2}+3.7431 \psi+0.1606 F_{p l}-0.0395 \psi F_{p l}- \\
& \quad 0.3133 \psi^{2}-3.9998 \times 10^{-3} F_{p l}{ }^{2}
\end{aligned}
$$

\begin{tabular}{|c|c|c|c|c|c|c|c|c|}
\hline \multirow{2}{*}{ Source } & \multicolumn{4}{|c|}{$T$} & \multicolumn{4}{|c|}{$G$} \\
\hline & Sum of squares & $d f$ & $F$ value & $p$ value & Sum of squares & $d f$ & $F$ value & $p$ value \\
\hline Model & $9011.42 / 9000.66$ & $9 / 5$ & $201.93 / 406.85$ & $<0.0001 /<0.0001$ & $16.93 / 16.90$ & $9 / 6$ & $34.84 / 61.85$ & $<0.0001 /<0.0001$ \\
\hline$A$ & $6147.56 / 6147.56$ & $1 / 1$ & $1239.82 / 1389.40$ & $<0.0001 /<0.0001$ & $0.59 / 0.59$ & $1 / 1$ & $10.84 / 12.85$ & $0.0058 / 0.0025$ \\
\hline$B$ & 1997.61/1997.61 & $1 / 1$ & $402.87 / 451.48$ & $<0.0001 /<0.0001$ & $12.85 / 12.85$ & $1 / 1$ & $238.00 / 282.15$ & $<0.0001 /<0.0001$ \\
\hline$C$ & 1.07 & 1 & 0.22 & 0.6492 & $2.34 / 2.34$ & $1 / 1$ & $43.26 / 51.28$ & $<0.0001 /<0.0001$ \\
\hline$A B$ & $210.54 / 210.54$ & $1 / 1$ & $42.46 / 47.58$ & $<0.0001 /<0.0001$ & $4.51 \times 10^{-3}$ & 1 & 0.08 & 0.7771 \\
\hline$A C$ & $35.70 / 35.70$ & $1 / 1$ & $7.20 / 8.07$ & $0.0188 / 0.0113$ & $4.51 \times 10^{-3}$ & 1 & 0.08 & 0.7771 \\
\hline$B C$ & 0.36 & 1 & 0.073 & 0.7915 & $0.22 / 0.22$ & $1 / 1$ & $4.10 / 4.86$ & $0.0641 / 0.0426$ \\
\hline$A^{2}$ & $607.92 / 609.25$ & $1 / 1$ & $122.60 / 137.70$ & $<0.0001 /<0.0001$ & 0.02 & 1 & 0.33 & 0.5758 \\
\hline$B^{2}$ & 8.68 & 1 & 1.75 & 0.2087 & $0.75 / 0.75$ & $1 / 1$ & $13.90 / 16.44$ & $0.0025 / 0.0009$ \\
\hline$C^{2}$ & 0.68 & 1 & 0.14 & 0.7171 & $0.17 / 0.17$ & $1 / 1$ & $3.09 / 3.64$ & $0.1025 / 0.0744$ \\
\hline Lack of fit & $0.84 / 11.60$ & $5 / 9$ & $0.02 / 0.16$ & $0.9997 / 0.9934$ & $6.47 \times 10^{-3} / 0.033$ & $5 / 8$ & $0.02 / 0.05$ & $0.9999 / 0.9999$ \\
\hline Pure error & $63.62 / 63.62$ & $8 / 8$ & & & $0.70 / 0.70$ & $8 / 8$ & & \\
\hline Cor total & $9075.88 / 9075.88$ & $22 / 22$ & & & $17.63 / 17.63$ & $22 / 22$ & & \\
\hline
\end{tabular}

Table 3 Variance analysis of regression models

Note: The data on the left of the oblique line are the variance analysis results obtained through the first calculation; while those on its right are the variance analysis results obtained through multiple recalculations after the most insignificant regression terms are eliminated one by one. $p<0.01$ for being highly significant; $0.01<p<0.05$ for being significant; $0.05<p<0.1$ for being slightly significant; $p>0.1$ for being insignificant.

3.3 Primary and secondary analysis on influences of experimental factors on evaluation indexes

To define the relative importance of influences of revolving speed of tumbler $\left(n_{2}\right)$, speed ratio between tumbler and carrier rollers $(\psi)$, and pre-load force of stretch film $\left(F_{p l}\right)$ on wrapping time $(T)$ and consumption of stretch film per unit mass of round 
bale $(G)$, according to Equations (7) and (8), the method of contribution rate was adopted to figure out contributions of experimental factors on evaluation indexes ${ }^{[29]}$. The corresponding results are shown in Table 4.

Table 4 Contributions of each experimental factor on each evaluation index

\begin{tabular}{ccccc}
\hline Items & $A$ & $B$ & $C$ & Sorting \\
\hline$T$ & 2.9059 & 1.9355 & 0.4278 & $A>B>C$ \\
$G$ & 0.9059 & 2.2966 & 2.0075 & $B>C>A$ \\
\hline
\end{tabular}

3.4 Analysis on influencing rules of experimental factors on evaluation indexes

According to the data on the right of the oblique line in Table 3 and sorting of contributions of each experimental factor on each evaluation index in Table 4, regression terms that had more important influences on evaluation indexes were selected, then MATLAB software and Design-Expert software were adopted to draw the four-dimensional slice diagram and the response surface respectively, so that the relevant influencing rules could be visually described.

In Table 3, the data on the right of the oblique line indicated that the interaction term of revolving speed of tumbler and speed ratio between tumbler and carrier rollers $(A B)$ had a highly significant influence on wrapping time $(T)$, while the interaction term of revolving speed of tumbler and pre-load force of stretch film $(A C)$ significantly affected wrapping time $(T)$. Considering this, the four-dimensional slice diagram was used to describe influential effects of revolving speed of tumbler $(A)$, speed ratio between tumbler and carrier rollers $(B)$, and pre-load force of stretch film $(C)$ on wrapping time $(T)$ in a visual manner, as shown in Figure 3.

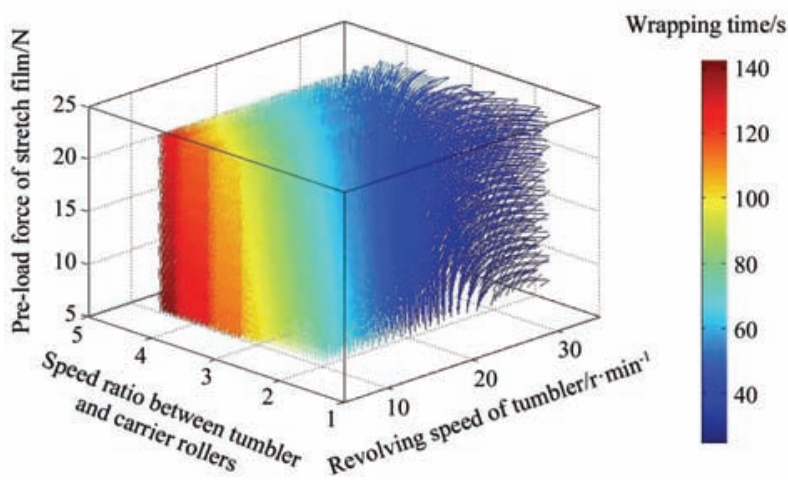

Figure 3 Four-dimensional slice diagram of revolving speed of tumbler, speed ratio between tumbler and carrier rollers, and pre-load force of stretch film on wrapping time

The overall effect trend of Figure 3 is shown as follows. Within the scope of the experiment, both the increase of revolving speed of tumbler and the decrease of speed ratio between tumbler and carrier rollers were rather beneficial to shorten wrapping time; or conversely, pre-load force of stretch film had a relatively low influence on wrapping time, which conformed to sorting of contributions of all experimental factors on wrapping time in Table 4. The reason was that within the range of the experiment, the increase of revolving speed of tumbler gave rise to the improvement of wrapping efficiency. Again, within this range, if speed ratio between tumbler and carrier rollers went down, according to Equation (5), it was clear that overlapping ratio of stretch films thus dropped, and the time required to fulfill one-layer wrapping for a single round bale was cut down. Hence, the time required by the completion of four-layer wrapping for a single round bale was shortened. In other words, wrapping time was reduced.

Likewise, according to the data on the right of the oblique line in Table 3, only the interaction term of speed ratio between tumbler and carrier rollers, and pre-load force of stretch film $(B C)$ had a significant influence on consumption of stretch film per unit mass of round bale $(G)$. Therefore, the response surface was used to describe such an influential effect visually ${ }^{[30]}$, when revolving speed of tumbler $(A)$ was fixed on the zero-level, as shown in Figure 4.

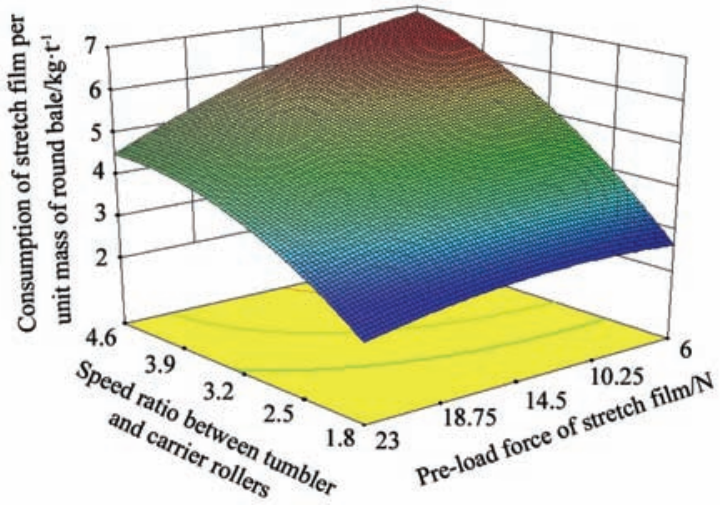

Figure 4 Response surface of pre-load force of stretch film, and speed ratio between tumbler and carrier rollers on consumption of stretch film per unit mass of round bale

The overall effect trend of Figure 4 is shown as follows. Within the scope of the experiment, both the decrease of speed ratio between tumbler and carrier rollers and the increase of pre-load force of stretch film were beneficial to bring consumption of stretch film per unit mass of round bale down. The reason was that within the range of the experiment, according to Equation (5), if speed ratio between tumbler and carrier rollers went down, overlapping ratio of stretch films also decreased; resultantly, the stretch film needed to fulfill one-layer wrapping for a single round bale reduced, so that the stretch film required by the completion of four-layer wrapping for a single round bale was also lessened. Then, according to Equation (6) and the mass of the round bale remaining unchanged, it was clear that the corresponding consumption of stretch film per unit mass of round bale went down. Also, within the scope of the experiment, if pre-load force of stretch film rose, the wrapping compactness went up as well, so was the deformation of stretch film during wrapping. Due to such a fact, less stretch films were needed to fulfill four-layer wrapping for a single round bale on the premise that the mass of such round bale kept unchanged. Again, according to Equation (6), consumption of stretch film per unit mass of round bale diminished correspondingly.

\subsection{Parameter optimization}

As relative importance and influencing rules of various experimental factors on evaluation indexes were different from each other, evaluation indexes should be taken into comprehensive consideration.

To make analysis more practical and study results more indicative, it could be known that there was rather preferable wrapping sealing property when overlapping ratio of stretch films ranged from $30 \%$ to $50 \%$ for the round bale, which could be obtained according to the relevant literatures ${ }^{[21,22]}$ and experiments. Moreover, according to Equation (5), at this time, speed ratio between tumbler and carrier rollers ranged from 2.6 to 3.6 correspondingly. Conforming to working performance 
requirements of the wrapping machine and the above analysis results, the defined constraint conditions included revolving speed of tumbler of $21.5-35 \mathrm{r} / \mathrm{min}$, speed ratio between tumbler and carrier rollers of 2.6-3.6, and pre-load force of stretch film of 20$23 \mathrm{~N}$. Moreover, the objective functions consisted of the shortest wrapping time and the minimum consumption of stretch film per unit mass of round bale. Then, according to Equations (7) and (8), Design-Expert software was utilized to optimize and obtain the relevant working parameters so that multiple parameter optimization combination schemes were acquired.

Comprehensively considering the relative importance of evaluation indexes as well as the stability of the round bale during wrapping, the optimal parameter combination scheme was selected from multiple parameter optimization combination schemes. In detail, revolving speed of tumbler ranged from $31 \mathrm{r} / \mathrm{min}$ to $32 \mathrm{r} / \mathrm{min}$, speed ratio between tumbler and carrier rollers was 2.6, and pre-load force of stretch film was between $20 \mathrm{~N}$ and $22 \mathrm{~N}$. Under such a circumstance, the corresponding wrapping time required was 37.7-38.9 s and consumption of stretch film per unit mass of round bale was $3.21-3.46 \mathrm{~kg} / \mathrm{t}$, which were the predicted values that acquired through the optimized regression models.

In order to test the optimized regression models and the reliability of parameter optimization results, validation experiment was conducted. Six combinations were selected from the above optimal parameter combination schemes to perform ten repeated experiments each by the tumbler-type round bale wrapping machine, and the associated operating conditions were identical to the experiment for twenty-three groups in Table 2. Then, the mean value was used as the measured value. The results of comparative analysis between the measured values and the predicted values are shown in Table 5 .

Table 5 Comparative analysis results of validation experiment

\begin{tabular}{ccccccc}
\hline & \multicolumn{3}{c}{ Experimental factors } & & \multicolumn{2}{c}{ Evaluation indexes } \\
\cline { 2 - 3 } \cline { 5 - 6 } No. & $A$ & $B$ & $C$ & $T$ & $G$ \\
\hline 1 & 31 & 2.6 & 20 & $37.7 / 37.5 / 0.53$ & $3.46 / 3.39 / 2.06$ \\
2 & 31 & 2.6 & 21 & $38.2 / 38.0 / 0.53$ & $3.35 / 3.33 / 0.60$ \\
3 & 31 & 2.6 & 22 & $38.7 / 38.3 / 1.04$ & $3.24 / 3.21 / 0.93$ \\
4 & 32 & 2.6 & 20 & $37.8 / 37.2 / 1.61$ & $3.43 / 3.41 / 0.59$ \\
5 & 32 & 2.6 & 21 & $38.3 / 37.9 / 1.06$ & $3.33 / 3.31 / 0.60$ \\
6 & 32 & 2.6 & 22 & $38.9 / 38.1 / 2.10$ & $3.21 / 3.19 / 0.63$ \\
\hline
\end{tabular}

Note: The units of data in $T$ column and $G$ column are s/s/\%, $\left(\mathrm{kg} \cdot \mathrm{t}^{-1}\right) /\left(\mathrm{kg} \cdot \mathrm{t}^{-1}\right) / \%$, respectively. In the three data disconnected by oblique lines, the data on the left side are the predicted values that acquired through the optimized regression models, the data in the intermediate position are the measured values that acquired through validation experiment, and the data on the right side are relative error between the predicted values and the measured values.

Relying on the comparative analysis results in Table 5, the predicted values and the measured values of evaluation indexes basically coincided with each other and the relative error fell below $5 \%$, which indicated that both the optimized regression models acquired through the wrapping experiment and the relevant parameter optimization results were reliable.

\section{Rice straw bale wrapping silage experiment}

A steel-roll round baler with a liquid addition device, which had been developed by this research group (dimension of the round bale is $\varnothing 500 \mathrm{~mm} \times 750 \mathrm{~mm}$, as shown in Figure $5 \mathrm{a}, 5 \mathrm{~b}$ and $5 \mathrm{c}$ ), and a tumbler-type wrapping machine (as shown in Figure 5d) were both utilized to carry out rice straw bale wrapping silage experiment in Heilongjiang Province.

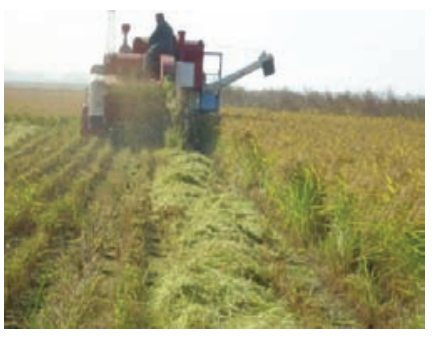

a. Paddy field harvested by conventional rice combine

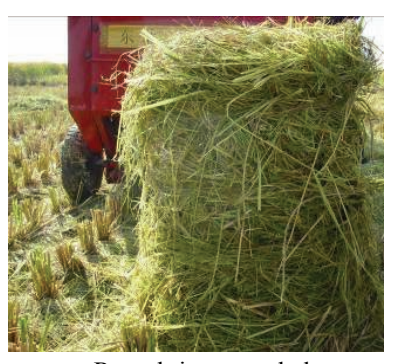

c. Round rice straw bale

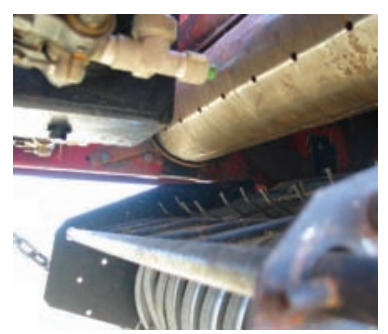

b. Steel-roll round baler with a liquid addition device

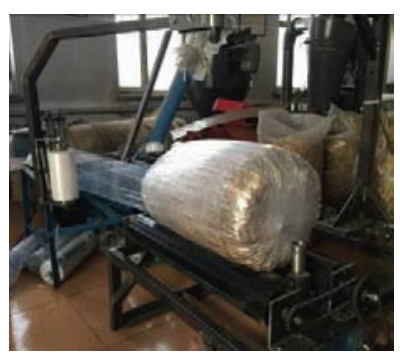

d. Wrapping machine
Figure 5 Rice straw bale wrapping silage experiment

The rice straw bale wrapping silage technology could be described as follows. A conventional rice combine was utilized to reap paddy rice and lay its straws in the paddy fields; then within one day after rice harvesting, steel-roll round baler with a liquid addition device was used to make these rice straws into round bale with lactic bacteria additive (BioPlus Silage of $1.8 \times 10^{10} \mathrm{CFU} / \mathrm{g}$, manufactured by Chr. Hansen Company of USA; the adding level was $3.0 \times 10^{5} \mathrm{CFU} / \mathrm{g}$ of fresh samples) ${ }^{[31]}$. The tumbler-type round bale wrapping machine that worked in a fixed manner was utilized for experiments, so round bales should be transported to the storage site in the first place; then, round bale wrapping was carried out by the wrapping machine (working parameters: $32 \mathrm{r} / \mathrm{min}$ for revolving speed of tumbler; 2.6 for speed ratio between tumbler and carrier rollers; $21 \mathrm{~N}$ for pre-load force of stretch film). In addition, three groups of experiments were performed when the number of layers of stretch film was four, five or six; and, for each group, the experiment was repeated for one hundred times, then wrapped rice straw bales were stored at normal temperature for forty-five days. Finally, $\mathrm{pH}$ values and chemical components of rice straws of different wrapping layers were tested and analyzed according to the determination method of the relevant literature ${ }^{[31]}$.

Determination and analysis results are given as follows. $\mathrm{pH}$ values corresponding to four, five or six stretch film layers were $4.07,3.98$ or 3.79 successively in terms of the round bale. The quality of rice straw silage was evaluated according to the existing "Silage Quality Evaluation Standard (2016)" of China. To be specific, the silage with a $\mathrm{pH}$ value no more than 3.8 is excellent, between 3.9 and 4.1 is good, between 4.2 and 4.7 is ordinary, and no less than 4.8 is inferior ${ }^{[31]}$. Comparing the chemical components analysis results with such an evaluation standard, it became clear that in the case of four, five and six stretch film layers, the quality grade of rice straw silage was good, good and excellent correspondingly; moreover, the quality of rice straw silage corresponding to five stretch film layers was superior to that of four stretch film layers. After chemical composition content determination was conducted for round bale with diverse wrapping layers, results were statistically analyzed. Furthermore, according to statistical analysis results, no significant differences lay in NDF, 
$\mathrm{ADF}$ and $\mathrm{CP}$ of rice straw silage with four, five and six stretch film layers. To sum up, in order to guarantee the quality of rice straw silage, the round bale should be wrapped by no less than five layers of stretch films through the utilization of the tumbler-type round bale wrapping machine.

\section{Conclusions}

1) A tumbler-type round bale wrapping machine based on wrapping silage with stretch film was designed, and it could satisfy the wrapping demands of round bales with a diameter/length between $500 \mathrm{~mm}$ and $1000 \mathrm{~mm}$, which was beneficial to boost the application of the wrapping machine in China.

2) By the wrapping experiment of tumbler-type round bale wrapping machine, the optimal parameter combination scheme was revolving speed of tumbler of 31-32 r/min, speed ratio between tumbler and carrier rollers of 2.6, and pre-load force of stretch film of 20-22 N. Under such a circumstance, the corresponding wrapping time required was 37.7-38.9 $\mathrm{s}$ and consumption of stretch film per unit mass of round bale was $3.21-3.46 \mathrm{~kg} / \mathrm{t}$. And, the predicted values and the measured values of evaluation indexes basically coincided with each other and the relative error fell below $5 \%$.

3) By the rice straw bale wrapping silage experiment, the round bale should be wrapped by no less than five layers of stretch films through the utilization of the tumbler-type round bale wrapping machine in order to guarantee the quality of rice straw silage.

\section{Acknowledgments}

The authors acknowledge that this work was financially supported by the National Natural Science Foundation of China (Grant No.51405076), and the 13th Five Years Key Programs for Science and Technology Development of China (Grant No.2016YFD0701300).

\section{[References]}

[1] Peng C Y, Luo H L, Kong J. Advance in estimation and utilization of crop residues resources in China. Chinese Journal of Agricultural Resources and Regional Planning, 2014; 35(3): 14-20. (in Chinese)

[2] Xu Y Y, Hou S L, Zhao L X, Meng H B, Tian Y S. Analysis for Straw Storage and Transportation at Home and Abroad. Journal of Agricultural Mechanization Research, 2014; 36(9): 60-64, 71. (in Chinese)

[3] Lei J L, Wang D F, Zhang Q C, Yang X, Li L Q, Li C. Experiment on stress relaxation characteristics of intact rice straw during rotary compression. Transactions of the CSAE, 2015; 31(8): 76-83. (in Chinese)

[4] Li C F, Zhou L, Wang H B. Design of Succulence Fodder Storage Technology and Bale Packer. Journal of Agricultural Mechanization Research, 2012; 34(6): 73-76. (in Chinese)

[5] Nonaka K. Studies on stable method for making of low-moisture round bale silage and evaluation of its quality. Research Bulletin of the National Agricultural Research Center for Hokkaido Region, 2002; 176(1): $1-55$.

[6] Du R, Ma Q S, Pan Y B, Xue J Q. Design and Research on the Machine Twining for Plastic Film Round Straw Bundle Cylinder. Journal of North China Institute of Astronautic Engineering, 2005; 15(2): 1-2, 17. (in Chinese)

[7] Walton J D. Bale wrapping machine: US, US5048271. 1991.

[8] Lacey L J, Hourihane C. A combined bale pressing and bale wrapping machine: Ireland, WO/2003/039240. 2003.
[9] Gresset P. Bale wrapping device: US, US20160037725. 2016.

[10] Dong Y, Chang R. Development situation of round bale wrapping machine at home and abroad. Agricultural Engineering, 2016; 6(1): 19-21. (in Chinese)

[11] Martinson K, Coblentz W, Sheaffer C. The effect of harvest moisture and bale wrapping on forage quality, temperature, and mold in orchard grass hay. Journal of Equine Veterinary Science, 2011; 31(12): 711-716.

[12] Coblentz W K, Coffey K P, Chow E A. Storage characteristics, nutritive value, and fermentation characteristics of alfalfa packaged in large-round bales and wrapped in stretch film after extended time delays. Journal of Dairy Science, 2016; 99(5): 3497-3511.

[13] Taylor R K, Blasi D A, Shroyer J P. Storage losses in net-wrapped, large round bales of alfalfa. Applied Engineering in Agriculture, 1994; 10(3): 317-320.

[14] Keller T, Nonn H, Jeroch H. The effect of sealing and of additives on the fermentation characteristics and mould and yeast counts in stretch film wrapped big-bale lucerne silage. Arch Anim Nutr, 1998; 51(1): 63-75.

[15] Paillat J M, Gaillard F. Air-tightness of wrapped bales and resistance of polythene stretch film under tropical and temperate conditions. Journal of Agricultural and Engineering Research, 2001; 79(1): 15-22.

[16] Borreani G, Bisaglia C, Tabacco E. Effects of a new-concept wrapping system on alfalfa round-bale silage. Transactions of the ASABE, 2007; 50(3): 781-787.

[17] Shinners K J, Huenink B M, Muck R E, Albrecht K A. Storage characteristics of large round and square alfalfa bales: low-moisture wrapped bales. Transactions of the ASABE, 2009; 52(2): 401-407.

[18] Bisaglia C, Tabacco E, Borreani G. The use of plastic film instead of netting when tying round bales for wrapped baled silage. Biosystems Engineering, 2011; 108(1): 1-8.

[19] Zeng Q H, Liu X F, Guo Y Z. Research on WM1071 traction type silage round bundle envelope machine research. Journal of Agricultural Mechanization Research, 2013; 35(11): 144-147, 152. (in Chinese)

[20] Wang D F, Jiang Y Y, Wang J Q. Structure-improving and experiment of steel-roll round baler. Transactions of the CSAM, 2010; 41(12): 84-88. (in Chinese)

[21] Bai C S, Yu Z, Xue Y L, Shan Z, Sun J J, Xu Q F, Li P. Effect of Wrapping Layers on Baled Alfalfa Silage. Acta Agrestia Sinica, 2007; 15(1): 39-42. (in Chinese)

[22] Liang H, Zuo F Y, Yuan Y, Wang Y C, Luo D, Zeng B, Xu J. Research progress of round bale silage technology. Acta Agrestia Sinica, 2014; 22(1): 16-21. (in Chinese)

[23] Qin W C, Xue X Y, Cui L F, Zhou Q Q, Xu Z F, Chang F L. Optimization and test for spraying parameters of cotton defoliant sprayer. Int J Agric \& Biol Eng, 2016; 9(4): 63-72.

[24] Xu C L, Zhang C L, Li L H, Li M J. Optimization of working parameters for puddling and flatting machine in paddy field. Int J Agric \& Biol Eng, 2016; 9(3): 88-96

[25] Gao W, Tabil L G, Zhao R F, Liu D J. Optimized design and experiment on ring mold pelletizer for producing biomass fuel pellets. Int J Agric \& Biol Eng, 2016; 9(3): 57-66.

[26] Yu H M, Zuo C C, Xie Q J. Parameter optimization for microwave coupled with hot air drying process of hawthorn slices using response-surface methodology. Int J Agric \& Biol Eng, 2015; 8(2): $121-134$.

[27] Liu L J, Yang H, Ma S C. Experimental study on performance of pneumatic seeding system. Int J Agric \& Biol Eng, 2016; 9(6): 84-90.

[28] Zhang W, Hou Y R, Liu X, Lian Q, Fu X M, Zhang B, et al. Wind tunnel experimental study on droplet drift reduction by a conical electrostatic nozzle for pesticide spraying. Int J Agric \& Biol Eng, 2017; 10(3): 87-94.

[29] Chen H T, Ming X L, Liu S, Zhang Y, Zhang H C. Optimization of technical parameters for making mulch from waste cotton and rice straw fiber. Transactions of the CSAE, 2015; 31(13): 292-300. (in Chinese)

[30] Niu K, Fang X F, Liu Y C, Lü C X, Yuan Y W. Optimized design and performance evaluation of an electric cup-chain potato metering device. Int J Agric \& Biol Eng, 2017; 10(2): 36-43.

[31] Wang D F, Buckmaster D R, Jiang Y Y, Hua J L. Experimental study on baling rice straw silage. Int J Agric \& Biol Eng, 2011; 4(1): 20-25. 